\title{
Parental Social Isolation and Child Maltreatment Risk during the COVID-19 Pandemic
}

\author{
Shawna J. Lee ${ }^{1}$ (D) Kaitlin P. Ward ${ }^{1} \cdot$ Joyce Y. Lee ${ }^{1} \cdot$ Christina M. Rodriguez $^{2}$ \\ Accepted: 27 December 2020 / Published online: 14 January 2021 \\ (C) The Author(s), under exclusive licence to Springer Science+Business Media, LLC part of Springer Nature 2021
}

\begin{abstract}
On March 11, 2020, COVID-19 was declared a pandemic by the World Health Organization. The social isolation and economic stress resulting from pandemic have the potential to exacerbate child abuse and neglect. This study examines the association of parents' perceived social isolation and recent employment loss to risk for child maltreatment (neglect, verbal aggression, and physical punishment) in the early weeks of the pandemic. Participants $(N=283)$ were adults living in the U.S. who were parents of at least one child 0-12 years of age. Participants completed an online survey approximately 2 weeks after the World Health Organization declared that COVID-19 was a pandemic. The survey asked about recent changes (i.e., in the past 2 weeks) to employment status, parenting behaviors, use of discipline, use of spanking, and depressive symptoms. Nearly $20 \%$ of parents had hit or spanked their child in the past two weeks alone. Parents' perceived social isolation and recent employment loss were associated with self-report of physical and emotional neglect and verbal aggression against the child, even after controlling for parental depressive symptoms, income, and sociodemographic factors. Parents' perceived social isolation was associated with parental report of changes in discipline, specifically, using discipline and spanking more often in the past 2 weeks. Associations were robust to analyses that included two variables that assessed days spent social distancing and days spent in "lockdown." Study results point to the need for mental health supports to parents and children to ameliorate the strain created by COVID-19.
\end{abstract}

Keywords Coronavirus · Global health crisis · Child neglect $\cdot$ Physical abuse $\cdot$ Child abuse $\cdot$ Parent-child conflict tactics scales · Physical punishment $\cdot$ Spank $\cdot$ Discipline $\cdot$ Parental depression

On March 11, 2020, COVID-19 was declared a pandemic by the World Health Organization (World Health Organization, 2020a). On March 16, 2020, the U.S. White House issued social distancing guidelines which instructed Americans to stay home if they feel sick, to work or engage in school from home, and to avoid social gatherings of more than ten people (The White House, Office of the Press Secretary, 2020). The economic stress and social isolation created by societal responses to the COVID-19 pandemic have potential to exacerbate child abuse and neglect, via widely acknowledged mechanisms linked to child maltreatment - specifically

Shawna J. Lee

shawnal@umich.edu

1 School of Social Work, University of Michigan, 1080 South University Ave, Ann Arbor, MI 48109, USA

2 University of Alabama, Birmingham, AL, USA unemployment and economic strain, social isolation, and parental depression.

By every measure, prior to the pandemic, child maltreatment was a major public health crisis in the U.S. (Wildeman, 2018, 2019). From 2014 to 2018, there was a staggering $8.4 \%$ increase in child maltreatment investigations (U.S. Department of Health and Human Services, 2020). In 2018, there were 678,000 child victims of maltreatment (U.S. Department of Health and Human Services, 2020). As alarming as these statistics are, annual child maltreatment statistics are an underestimate of the scope of child maltreatment, because annual statistics fail to capture the cumulative risk of maltreatment across childhood (Wildeman, 2019). Synthetic cohort analyses suggest that by the age of $18,12 \%$ of all U.S. children will have a substantiated case of maltreatment (Wildeman et al., 2014).

In the week following the pandemic announcement by the World Health Organization (World Health Organization, 2020b), and immediately before this research was launched on March 24, 2020 (i.e., week ending on March 21, 2020), the 
U.S. Department of Labor reported that 2.9 million people filed for unemployment, which was a 1000-fold increase from the previous week (U.S. Department of Labor, 2020, March). Economic strain and unemployment make it difficult for parents to meet their children's basic needs (Conger \& Conger, 2002; Conrad-Hiebner \& Byram, 2020; Neppl et al., 2016), thus raising concern that rates of child neglect would increase. The link between poverty and child maltreatment is wellestablished (Cancian, et al., 2010; Slack et al., 2004; Slack et al., 2011), wherein food insecurity and housing insecurity contribute to child abuse and neglect (Marcal, 2018; Slack et al., 2011; Wood et al., 2012). Given the historic economic crisis unfolding during the pandemic, the risks for families to slide into poverty - as well as experience food and housing insecurity - will mount.

In addition to the immediate possibility of more parents being unable to meet their children's physical needs, thus increasing the risk for child neglect, financial concerns tend to erode parents' mental health functioning (McConnell et al., 2011). Parents reporting elevated distress are at higher risk to engage in physical neglect (Lee, 2013; Slack et al., 2011; Stith et al., 2009) as well as maternal and paternal physical abuse (Kim et al., 2014; Lee et al., 2011; Miragoli et al., 2018; Schaeffer et al., 2005; Tucker et al., 2017). Initial reports suggested that depression rose in the days immediately following the start of the COVID-19 pandemic (Wang et al., 2020). Such evidence of mental health challenges may translate to an escalation in the risk for child maltreatment and neglect (Rodriguez et al., 2016; Stith et al., 2009). Depression in particular is implicated as a potent risk factor for both child abuse (Espinosa et al., 2017; Schaeffer et al., 2005) and child neglect (Lee et al., 2012). With robust effect sizes reported between depression and child abuse and neglect (Stith et al., 2009), increases in depression also predict subsequent increases in psychological aggression toward children among mothers already involved with child welfare (Conron et al., 2009). Higher levels of depression have also been observed in mothers of maltreated children relative to a matched sample of mothers (Mennen \& Trickett, 2011). Consequently, depression has been a consistent predictor of child abuse and neglect predating the COVID-19 pandemic.

State of Emergency declarations in many states required school closures, cancellation of large and small activities, and restrictions on movement outside the home. Although required in order to prevent disease spread, social distancing removed social, educational, and community supports that buffer parents in times of crisis. Indeed, research shows that parents who are at risk to engage in physical child abuse are less likely to perceive their social networks as satisfying (Ono \& Honda, 2017; Schaeffer et al., 2005), and lower social support satisfaction predicts increases in child abuse risk over time (Rodriguez et al., 2018). In contrast, greater perceived social support is associated with lower risk of child neglect
(Freisthler et al., 2014; Stith et al., 2009) as well as lower physical child abuse risk in both mothers and fathers (Rodriguez et al., 2016; Smith Slep \& O'Leary, 2007). Social support is conceptualized as a resource parents can access, serving a protective function by decreasing parents' stress to reduce their abuse risk (Tracy et al., 2018; Tucker \& Rodriguez, 2014). Given the guidelines of the pandemic, social support as a critical asset was thereby curtailed for many parents.

The current study examined whether parents' perceived difficulty in parenting due to social isolation and social distancing, as well as recent changes in employment status, were associated with child physical neglect, emotional neglect, verbal aggression, and physical punishment in the 2 weeks following announcement of the COVID-19 pandemic. Our main hypothesis was that parents' perceived difficulty in parenting due to social isolation and social distancing would be significantly associated with risk for child maltreatment - including neglect, verbal aggression, and physical punishment - even beyond what is attributable to the robust predictors of child maltreatment such as unemployment, income, and depression. In addition, we examined whether parents' perceived difficulty in parenting due to social isolation and social distancing, employment status, and depression were related to parents' reports of changes in their neglect or discipline use since COVID-19. We conducted additional analyses examining whether associations were robust to the inclusion of variables that measured actual time (i.e., number of days) spent social distancing and in lockdown.

\section{Methods}

\section{Design}

Data were collected via an online survey that was administered through Prolific, a company that conducts survey research (Palan \& Schitter, 2018). The survey was launched on March 24, 2020, nearly 2 weeks after the World Health Organization declared that the coronavirus was a pandemic (World Health Organization, 2020a, b), and 1 week after the White House issued social distancing guidelines to slow the spread of COVID-19. Participants who met the study criteria were sent an email from Prolific regarding their eligibility to participate in the survey. Participants were provided with a brief description of the survey via the Prolific website. In order to be eligible, individuals had to have U.S. nationality and be age 18 or older. If they chose to participate in the survey, they were linked through the Prolific platform to a Qualtrics survey designed and managed by the research team. There is no response rate to report because this study utilized a convenience sampling approach, wherein only those individuals who actively chose to participate in the study could 
participate. Thus, there was no predetermined sampling frame to reference to calculate a response rate. The research team did set a predetermined target enrollment number, and when that number was reached the survey automatically closed. Furthermore, we do not have information on individuals who might have viewed the study details on the Prolific platform but decided not to participate, or on individuals who wished to participate after enrollment for the survey was already closed. Notably, it took less than $24 \mathrm{~h}$ for the survey to reach its target enrollment number.

After reviewing the study information and providing informed consent, participants completed the online survey and received $\$ 6.00$ in payment, which was administered directly to participants via Prolific. The average completion time was $40 \mathrm{~min}$ long (range: $14-84 \mathrm{~min}$ ). To ensure the quality of the data, three attention checks were embedded throughout the survey. None of the participants failed more than one of the attention checks. All data provided to the research team were anonymous and contained no identifying information. This study was deemed exempt from oversight by the University of Michigan Institutional Review Board.

\section{Study Participants}

This was a national survey, with participants located throughout the U.S. A total of 555 adults residing in the U.S. completed the survey. The analytic sample for the current study included parents with at least one child living at home between the ages of $0-12$ years $(N=283$, or $51.0 \%$ of the total sample). Approximately $58.2 \%$ were mothers. As seen in Table 1, the average age was 35 years. The majority of the participants had at least a bachelor's degree (53.4\%) and identified as White (73.4\%). Average household income in the prior year was between $\$ 50,000$ and $\$ 70,000$. Approximately $21.2 \%$ of participants indicated their employment status had changed due to COVID-19.

\section{Dependent Variable Measures}

Parent-Child Conflict Tactics Scales (CTS-PC) (Straus et al., 1998) items were used to assess risk for physical neglect, emotional neglect, verbal aggression, and physical abuse. The CTS-PC response scale typically asks about the occurrence of behaviors within the past year. In this study, it was necessary to ask about behaviors since COVID-19, so the response scale was modified to ask how often behaviors occurred "in the past 2 weeks" (never, once, a few times, more than half the days, nearly every day, or every day). Risk for physical neglect was measured with 2 items: "had to leave child(ren) home alone, even when you thought some other adult should be with him/ her" and "were not able to make sure your child(ren) got the food they needed." A dichotomous variable was created to indicate no physical neglect (coded 0 ) or one or more instances of physical neglect (coded 1) in the past 2 weeks. Risk for emotional neglect was measured with 2 items: "were so caught up with your own problems that you were not able to show or tell your child that you loved him/her" and "were so drunk or high that you had a problem taking care of your child(ren)." A dichotomous variable was created to indicate no emotional neglect (coded 0 ) or one or more instances of emotional neglect (coded 1) in the past 2 weeks. Verbal aggression was measured with one item: "Shouted, yelled, or screamed at child(ren)." A dichotomous variable was created to indicate no verbal abuse (coded 0 ) or one or more instances of verbal abuse (coded 1 ) in the past 2 weeks. Physical punishment was measured with 2 items: "spanked child(ren)" and "slapped child(ren) on the hand, arm or leg." A dichotomous variable was created to indicate no physical punishment (coded 0) or one or more instances of physical punishment (coded 1 ) in the past 2 weeks.

Increases in Parental Neglect and Discipline since COVID-19 Lacking a baseline measurement of how frequently parents used these behaviors prior to COVID-19, parents were asked to report: "Since approximately 2 weeks ago, when the Coronavirus/Covid-19 global health crisis began:" "I have increased the use of discipline with my child(ren)"; "I have yelled at/screamed at my child(ren) more often than usual"; "I have had more conflicts with my child(ren) than usual"; "I have had to leave my child(ren) home alone more often than usual" and "I have spanked or hit my child(ren) more often than usual" ( $0=$ no, $1=y e s, 2=$ not applicable). For analysis, participants who chose "not applicable" were coded as missing.

\section{Independent Variables}

Parental Perceived Social Isolation Participants were asked, "Since the Coronavirus/Covid-19 global health crisis began, how true is it for you:" "Felt like social isolation/ social distancing makes it difficult to parent your child(ren)" $(0=$ never true, $1=$ sometimes true, $2=$ often or $3=$ almost always true).

Change in Employment Due to COVID-19 A dichotomous variable indicated whether participants had experienced an employment change due to COVID-19: "Has your employment status changed (e.g., laid off, furloughed) in the last 2 weeks because of the Coronavirus/Covid-19 global health crisis?" $(0=$ no, $1=$ yes $)$.

\section{Control Variables}

Depression The 8-item Personal Health Questionnaire (PHQ8) (Kroenke et al., 2009) is a validated diagnostic tool to measure severity of depressive disorders in the general population. PHQ items asked, "Over the last 2 weeks, how often 
Table 1 Descriptive statistics of study variables $(\mathrm{N}=283)$

\begin{tabular}{|c|c|c|c|c|c|c|}
\hline & $\mathrm{N}$ & $\%$ & Min & Max & M & SD \\
\hline Parental perceived social isolation & & & 0 & 3 & 0.77 & 0.91 \\
\hline Depressive symptoms & & & 0 & 24 & 7.54 & 6.22 \\
\hline Employment loss or change in past 2 weeks & 60 & 21.2 & & & & \\
\hline Physical neglect in past 2 weeks & 35 & 12.4 & & & & \\
\hline Emotional neglect in past 2 weeks & 65 & 23.0 & & & & \\
\hline Verbal aggression in past 2 weeks & 175 & 61.8 & & & & \\
\hline Physical punishment in past 2 weeks & 56 & 19.9 & & & & \\
\hline Increased use of discipline in past 2 weeks & 41 & 15.1 & & & & \\
\hline $\begin{array}{l}\text { Yelled at/screamed at my child(ren) more } \\
\text { than usual in past } 2 \text { weeks }\end{array}$ & 51 & 19.3 & & & & \\
\hline $\begin{array}{l}\text { Had more conflict with my child(ren) than } \\
\text { usual in past } 2 \text { weeks }\end{array}$ & 67 & 24.4 & & & & \\
\hline $\begin{array}{l}\text { Spanked or hit my child(ren) more than usual } \\
\text { in past } 2 \text { weeks }\end{array}$ & 13 & 5.4 & & & & \\
\hline Female & 164 & 58.2 & & & & \\
\hline White (non-Hispanic) & 207 & 73.4 & & & & \\
\hline Age & & & 21 & 56 & 35.11 & 6.89 \\
\hline Education & & & 1 & 5 & 3.25 & 1.27 \\
\hline Income & & & 1 & 7 & 4.76 & 1.93 \\
\hline Number of children & & & 1 & 10 & 2.04 & 1.22 \\
\hline Social distancing days & & & 0 & 30 & 9.95 & 5.54 \\
\hline Lockdown days & & & 0 & 20 & 5.43 & 4.31 \\
\hline
\end{tabular}

Note: Education had 5 categories: 1 =high school or less, $2=$ some college, $3=$ associate degree, $4=$ bachelor's degree, $5=$ master's, professional, or doctorate degree. Income had 7 categories: $1=\$ 10-20 \mathrm{k}, 2=\$ 20-30 \mathrm{k}$, $3=\$ 30-40 \mathrm{k}, 4=\$ 40-50 \mathrm{k}, 5=\$ 50-70 \mathrm{k}, 6=\$ 70-90 \mathrm{k}, 7=\$ 90 \mathrm{k}$ or more have you been bothered by any of the following problems?" The 8 items included, "Little interest or pleasure in doing things," "Feeling down, depressed, or hopeless," "Feeling tired or having little energy" and were assessed on a 4-point response scale from $0=$ not at all, $1=$ several days, $2=$ more than half the days, and $3=$ nearly every day. A sum score $(\alpha=$ $.91)$ of the 8 items was created for analyses.

Sociodemographic Controls Participants' sex $(0=$ male, $1=$ female $)$, cohabitation $(0=$ not cohabitating, $1=$ cohabitating $)$, race $(0=$ non-White, $1=$ White $)$, education level (treated as a continuous variable: 1=high school or less, 2=some college, 3=associate degree, 4=bachelor's degree, $5=$ master's, professional, or doctorate degree), age (in years), total household income in the last year before taxes (treated as a continuous variable: $1=\$ 10-20 \mathrm{k}, 2=\$ 20-30 \mathrm{k}, 3=\$ 30-40 \mathrm{k}$, $4=\$ 40-50 k, 5=\$ 50-70 k, 6=\$ 70-90 k, 7=\$ 90 k$ or more $)$, and number of children in the household were included as sociodemographic controls.

Social Distance and Lockdown Two additional variables assessed participants' actual time spent social distancing or in lockdown. Participants were asked: "Are you currently engaging in 'social distancing' (e.g., avoiding large groups, limiting contact with others)?" If yes, participants were asked, "About how many days ago did you start practicing social distancing?" Participants were also asked, "Are you currently engaging in 'lockdown' (e.g., sheltering-in-place, only going out for essential activities)?" If yes, "About how many days ago did you go on lockdown?" Both variables were continuous and ranged from 0 to 30 days.

\section{Analysis Plan}

Data cleaning and descriptive analyses were run in Stata version 15.1. All regression analyses were run in Mplus version 8 (Muthén \& Muthén, 1998-2017). For analyses with dichotomous dependent variables (i.e., parent-to-child neglect, verbal aggression, physical aggression, and parental discipline), we conducted logistic regression analyses using Maximum Likelihood estimation and Monte Carlo integration (1000 iterations), which produced odds ratio coefficients. An odds ratio of 1 indicates there is no association between the predictor and the odds of the outcome variable occurring; an odds ratio greater than 1 indicates the odds are increased for a particular outcome occurring; and an odds ratio less than 1 indicates odds are decreased for a particular outcome occurring. It is important to note that odds ratios and their confidence 
intervals tend to overinflate when sample cell sizes are small (Nylund, Asparouhov, \& Muthen, 2006). Given that the sample size for this study was relatively small $(N=283)$, estimates with large confidence intervals should be interpreted with caution.

All analyses controlled for symptoms of parental depressive symptoms in the past 2 weeks, sex (male/ female), race, education level, age in years, total household income in the last year, and number of children. To determine whether the estimates of perceived social isolation on maltreatment risk were robust to the reported number of days engaged in social distancing and lockdown, robustness checks used two variables that assessed the number of days spent in social distancing and lockdown since the COVID19 pandemic.

Missing data were relatively few. Key independent and dependent variables had $<1 \%$ missing data, except for increases in spanking (14.5\%), increases in yelling or screaming (6.4\%), increases in the use of discipline (3.9\%), and increases in conflict $(2.8 \%)$. Control variables had $<5 \%$ missing data. To handle missing data, regression analyses were conducted using full-information maximum likelihood estimation (FIML) analyses.

\section{Results}

\section{Descriptive Results}

Table 1 reports study descriptive statistics for the sample characteristics as well as the key independent and dependent variables. Participants had been engaged in social distancing for an average of 10 days and had been on lockdown for an average of 5 days. Participants' average perceived difficulty in parenting due to social distancing/isolation was 0.77 ranging from 0 to 3 . A PHQ- 8 cutpoint of $\geq 10$ can be used as an indicator of major depression (Kroenke et al., 2009); 33.6\% of the parents in this study met the PHQ-8 cutpoint for major depression.

\section{Physical and Emotional Neglect (Table 2)}

A one-unit increase in parental perceived social isolation (e.g., moving from 0 to 1 ) was associated with a $71 \%$ increase in the odds of parents physically neglecting their children (OR = $1.71, p=.05)$. Additionally, a one-unit increase in parental perceived social isolation was associated with an $84 \%$ increase in the odds of emotional neglect $(\mathrm{OR}=1.84, p<$ .01 ). Experiencing an employment change was not significantly associated with physical neglect $(\mathrm{OR}=2.33, p=$ $.063)$; however, experiencing an employment change was associated with a $151 \%$ increase in the odds of emotional neglect $(\mathrm{OR}=2.51, p<.05)$.

\section{Verbal Aggression (Table 2)}

A one-unit increase in parental perceived social isolation was associated with a $103 \%$ increase in the odds of shouting, yelling, or screaming ( $\mathrm{OR}=2.03, p<.001)$. Experiencing an employment status change due to the pandemic was not associated with verbal aggression ( $\mathrm{OR}=1.23, p=.543)$.

\section{Physical Punishment (Table 2)}

Parental perceived social isolation was not associated with spanking or slapping $(\mathrm{OR}=1.17, p=.412)$. However, experiencing an employment status change due to the pandemic was associated with a $275 \%$ increase in the odds of spanking or slapping $(\mathrm{OR}=3.75, p<.001)$.

\section{Increases in Discipline and Neglect (Table 3)}

A one-unit increase in parental perceived social isolation was associated with a $55 \%$ increase in the odds of parents using more discipline (OR $=1.55, p<.05)$; a $77 \%$ increase in the odds of parents yelling or screaming at their child(ren) more often than usual $(\mathrm{OR}=1.77, p<.01)$; a $92 \%$ increase in the odds of parents having more conflicts with their child(ren) than usual $(\mathrm{OR}=1.92, p<.001)$; a $132 \%$ increase in the odds of parents leaving their child alone more often than usual (OR $=2.32, p<.05)$; and a $124 \%$ increase in the odds of spanking or hitting child(ren) more often than usual (OR $=2.24, p<$ $.05)$. There were no observed effects for employment changes due to COVID-19 for any of the variables measuring parents' increased use of discipline, yelled/ screamed more than usual, had more conflicts than usual, had to leave child(ren) home alone more than usual, or spanked or hit more than usual in the past 2 weeks.

\section{Robustness Checks}

After finalizing the models as reported in Tables 2 and 3, robustness checks were conducted with analyses that included two variables assessing how many days the participant indicated they had spent social distancing or in lockdown. All results reported in Tables 2 and 3 were robust to the inclusion of these controls (and, in many cases, odds ratio coefficients increased and $p$-values decreased), suggesting that parents' perceptions of social isolation was a significant factor, even after accounting for the amount of time they had spent social distancing or in lockdown. Within these robustness checks, social distancing days and lockdown days were not significantly associated with any of the dependent variables, with one exception: a one-day increase in social distancing was associated with a $14 \%$ increase in the odds of spanking/ hitting child(ren) more often than usual $(\mathrm{OR}=1.14, p<.05)$. 
Table 2 Logistic regression analyses predicting parenting behaviors in the past 2 weeks

\begin{tabular}{|c|c|c|c|c|c|c|c|c|}
\hline \multirow[t]{2}{*}{ In the past 2 weeks: } & \multicolumn{2}{|c|}{ Physical neglect } & \multicolumn{2}{|c|}{ Emotional neglect } & \multicolumn{2}{|c|}{ Verbal aggression } & \multicolumn{2}{|c|}{ Physical punishment } \\
\hline & OR & $95 \% \mathrm{CI}$ & OR & $95 \% \mathrm{CI}$ & OR & $95 \% \mathrm{CI}$ & OR & $95 \% \mathrm{CI}$ \\
\hline Social isolation & $1.71^{*}$ & {$[1.11,2.63]$} & $1.84 * *$ & {$[1.30,2.61]$} & $2.03 * * *$ & {$[1.44,2.88]$} & 1.17 & {$[0.81,1.69]$} \\
\hline Employment change & 2.33 & {$[0.95,5.67]$} & $2.51 *$ & {$[1.23,5.15]$} & 1.23 & {$[0.63,2.39]$} & $3.75 * * *$ & {$[1.84,7.63]$} \\
\hline Major depression & $1.10^{*}$ & {$[1.02,1.18]$} & $1.12 * * *$ & {$[1.05,1.18]$} & 1.03 & {$[0.98,1.08]$} & 1.00 & {$[0.94,1.06]$} \\
\hline Female & 0.54 & {$[0.23,1.25]$} & 0.55 & {$[0.28,1.09]$} & 1.52 & {$[0.88,2.65]$} & $0.43^{*}$ & {$[0.22,0.84]$} \\
\hline White (non-Hispanic) & $0.36^{*}$ & {$[0.15,0.86]$} & 0.55 & {$[0.26,1.12]$} & 0.97 & {$[0.54,1.75]$} & $0.47^{*}$ & {$[0.24,0.97]$} \\
\hline Age & 0.54 & {$[0.95,1.09]$} & $1.07 * *$ & {$[1.02,1.13]$} & 0.99 & {$[0.95,1.03]$} & 0.97 & {$[0.92,1.02]$} \\
\hline Education & 1.39 & {$[0.93,2.09]$} & 1.10 & {$[0.80,1.50]$} & 0.99 & {$[0.78,1.27]$} & 1.19 & {$[0.86,1.64]$} \\
\hline Income & 1.04 & {$[0.79,1.36]$} & 1.05 & {$[0.85,1.30]$} & 0.93 & {$[0.78,1.10]$} & $0.72 * *$ & {$[0.58,0.90]$} \\
\hline Number of children & 0.73 & {$[0.48,1.12]$} & 0.80 & {$[0.59,1.09]$} & $1.31 *$ & {$[1.02,1.68]$} & 1.17 & {$[0.94,1.06]$} \\
\hline
\end{tabular}

Note: $\mathrm{OR}=$ odds ratio. $* p<05, * * p<.01, * * * p<.001$

\section{Discussion}

Prior research indicates that family violence, child maltreatment and interpersonal violence increase following natural disasters (Harville et al., 2011; Hawkins, 2009; Seddighi et al., 2019) as well as during economic recessions (Schneider et al., 2017). The critical public health policies intended to protect the public from the spread of COVID-19, such as closing face-to-face education, social distancing, and sheltering in place, leave many American children vulnerable to maltreatment (Baron et al., 2020; Bullinger et al., 2020; Herrenkohl et al., 2020).

The results of this study provided support for our key hypothesis that parents' perceived difficulty in parenting due to social isolation would be significantly associated with risk for child maltreatment. In the weeks immediately following the announcement of the COVID-19 pandemic and the social distancing guidelines issued by the U.S. White House, parental perceived social isolation - i.e., the extent to which parents indicated that social isolation and social distancing made it difficult for them to parent - was related to risk of physical and emotional neglect and verbal aggression toward the child (shouted, yelled, or screamed at children), measured using items from a validated scale of parent-to-child risk for child maltreatment (CTS-PC) (Straus, et al., 1998). Significant associations held even when accounting for predictors of child maltreatment such as unemployment, income, and parental depression, and were also robust to analyses that included variables assessing days spent social distancing and days spent in lockdown. Consequently, the current findings underscore that parents perceive that their social isolation is interfering with their parenting after accounting for actual time spent in isolation. These results are consistent with research showing that social isolation was associated with greater risk

Table 3 Logistic regression analyses predicting parental self-report of increased conflicts and neglect in the past 2 weeks

\begin{tabular}{|c|c|c|c|c|c|c|c|c|c|c|}
\hline \multirow{2}{*}{$\begin{array}{l}\text { Since approximately } 2 \text { weeks } \\
\text { ago, when the Coronavirus/ } \\
\text { COVID-19 global health } \\
\text { crisis began, I have... }\end{array}$} & \multicolumn{2}{|c|}{$\begin{array}{l}\text { Increased use of } \\
\text { discipline with my } \\
\text { children }\end{array}$} & \multicolumn{2}{|c|}{$\begin{array}{l}\text { Yelled at/ screamed at } \\
\text { my child(ren) more } \\
\text { than usual }\end{array}$} & \multicolumn{2}{|c|}{$\begin{array}{l}\text { Had more conflicts } \\
\text { with my child(ren) than } \\
\text { usual }\end{array}$} & \multicolumn{2}{|c|}{$\begin{array}{l}\text { Had to leave my } \\
\text { child(ren) alone more } \\
\text { often than usual }\end{array}$} & \multicolumn{2}{|c|}{$\begin{array}{l}\text { Spanked or hit my } \\
\text { child(ren) more than } \\
\text { usual }\end{array}$} \\
\hline & OR & $95 \% \mathrm{CI}$ & OR & $95 \% \mathrm{CI}$ & OR & $95 \% \mathrm{CI}$ & OR & $95 \% \mathrm{CI}$ & OR & $95 \% \mathrm{CI}$ \\
\hline Social isolation & $1.55^{*}$ & {$[1.05,2.28]$} & $1.77 * *$ & {$[1.25,2.53]$} & $1.92 * * *$ & {$[1.38,2.68]$} & $2.32 *$ & {$[1.09,4.93]$} & $2.24 *$ & {$[1.11,4.51]$} \\
\hline Employment changed & 1.17 & {$[0.50,2.73]$} & 1.02 & {$[0.46,2.22]$} & 0.99 & {$[0.47,2.08]$} & 1.91 & {$[0.40,9.03]$} & 1.14 & {$[0.25,5.31]$} \\
\hline Major depression & $1.09 * *$ & {$[1.02,1.16]$} & $1.07 *$ & {$[1.01,1.14]$} & $1.11 * * *$ & {$[1.05,1.18]$} & $1.15^{*}$ & {$[1.01,1.31]$} & 1.10 & {$[0.98,1.23]$} \\
\hline Female & 1.54 & {$[0.70,3.39]$} & 0.85 & {$[0.42,1.72]$} & 0.95 & {$[0.49,1.84]$} & 0.32 & {$[0.07,1.49]$} & 0.28 & {$[0.07,1.12]$} \\
\hline White (non-Hispanic) & 0.47 & {$[0.21,1.06]$} & 1.29 & {$[0.58,2.89]$} & 1.07 & {$[0.51,2.26]$} & 0.64 & {$[0.12,3.54]$} & 0.88 & {$[0.21,3.69]$} \\
\hline Education & 1.15 & {$[0.81,1.64]$} & 0.94 & {$[0.68,1.30]$} & 0.94 & {$[0.70,1.27]$} & 0.88 & {$[0.42,1.83]$} & 1.46 & {$[0.73,2.91]$} \\
\hline Age & 1.03 & {$[0.97,1.10]$} & 1.05 & {$[1.00,1.11]$} & 1.01 & {$[0.96,1.06]$} & 0.98 & {$[0.86,1.12]$} & 1.01 & {$[0.90,1.13]$} \\
\hline Income & 1.18 & {$[0.92,1.51]$} & 1.06 & {$[0.85,1.32]$} & 1.23 & {$[0.99,1.52]$} & 1.15 & {$[0.70,1.90]$} & 0.80 & {$[0.51,1.26]$} \\
\hline Number of children & 0.88 & {$[0.63,1.22]$} & 0.96 & {$[0.72,1.28]$} & 0.95 & {$[0.72,1.27]$} & $0.36^{*}$ & {$[0.13,0.98]$} & $0.37 *$ & {$[0.15,0.93]$} \\
\hline
\end{tabular}

Note: $\mathrm{OR}=$ odds ratio. $* p<05, * * p<.01, * * * p<.001$ 
of neglect during the pandemic (Bullinger et al., 2020) and a longitudinal study that showed that loneliness during the pandemic related to increases in parents' use of behaviors such as hitting, spanking, and verbal aggression during the pandemic (Rodriguez et al., 2020).

In the current study, perceived parental social isolation was not associated with physical punishment (slapping/spanking) using the CTS-PC. However, perceived parental social isolation was associated with a $124 \%$ increase in parents' selfreport of spanking or hitting their children more than usual since the COVID-19 global health crisis began. Analyses indicated that a one-day increase in social distancing was associated with a $14 \%$ increase in the odds of more spanking or hitting since the pandemic. Notably, nearly $20 \%$ of parents said they had hit or spanked their child in the past two weeks alone. Thus, taken as a whole, implications are twofold. First, physical punishment was common during this period, with one in five parents indicating they had hit their child in just the past 2 weeks. Second, parents felt that they were using physical punishment more often during the pandemic. Although social isolation was not associated with slapping and spanking in the current results, a recent longitudinal study comparing mothers' use of spanking controlling for prepandemic scores showed increases in mothers' use of spanking (Rodriguez et al., 2020). In the current study, changes in employment status were significantly associated with increased risk of physical punishment, which is consistent with prior research showing that unemployment status may increase risks associated with abuse and neglect (Slack et al., 2004, 2011). The results suggested that when parents were spending more time with children (social distancing) and experienced the stress of employment loss, risk for physical punishment of children increased.

Because the survey in the current study was administered after the pandemic had started, there were no baseline or pre-pandemic measures of parenting behaviors and child maltreatment risk. To address this limitation, the survey asked parents about whether they had increased their use of behaviors in the past 2 weeks, since the pandemic began. Although it would be ideal to have pre-pandemic measures of parenting behaviors and child maltreatment risk to assess whether there was an increase in behaviors following the pandemic (see Rodriguez et al., 2020), the questions related to increased use of parenting risk behaviors serve as a rough proxy for a time lagged design. Analyses of these items (Table 3 ) showed a similar pattern of results to the CTS-PC items (Table 2). Specifically, parents' perceived social isolation was associated with all of the items measuring increased conflict, including parents' increased use of discipline, yelled or screamed more at my children, had more conflicts with my children, had to leave children alone more than usual, and spanked or hit my children more than usual. The pattern of results were consistent with longitudinal research assessing changes in mothers' pre-pandemic parenting behavior relative to mothers' parenting behaviors during the pandemic (Rodriguez et al., 2020).

In addition, the current study results suggested that perceived parental social isolation may be associated with increased risk for child maltreatment, thus extending prior research showing that social isolation and lack of social support are risk factors for child maltreatment (Ono \& Honda, 2017; Rodriguez et al., 2018; Schaeffer et al., 2005; Tucker \& Rodriguez, 2014), even after accounting for the associations with parental depressive symptoms (Dubowitz et al., 2011; Lee, 2013; Lee et al., 2012; Mennen \& Trickett, 2011; Stith et al., 2009) and unemployment or economic strain (Cancian et al., 2010; Slack et al., 2004). The emotional and psychological strains of perceived social isolation during a pandemic may be problematic for many adults who are parenting at least one child under the age of 12, after accounting for other challenging circumstances such as changes in employment status and parental depression. We conducted robustness checks to examine whether actual time spent in social isolation or lockdown were explaining the results related to social isolation. That is, parents who have spent more time in social isolation or lockdown may indeed experience increasing level of strain on parenting, particularly as social isolation removes key parenting supports such as babysitters, childcare, teachers, and others who provide care to children. However, the robustness checks indicated parents' perception of social isolation remained even after accounting for days in social isolation and days in lockdown days. This suggests that parents' perceptions of social isolation may be more critical than the actual days spent in isolation, at least in this early phase of the pandemic. Future research should explicitly examine the relative importance of parents' subjective experience of isolation over the more objective time spent in isolation in exacerbating child maltreatment risk as the current findings imply the former is more critical.

Depression was common among the respondents in this study, with one out of three parents reporting symptoms of depression that met the criteria for major depression using the PHQ-8 (Kroenke et al., 2009). As discussed in other research (Lee et al., 2020), this is notably higher than the rates of depression observed prior to COVID-19. During April 23May 5 2020, the nationally representative U.S. Household Pulse Survey indicated that approximately $24 \%$ of U.S. adults had symptoms of depressive disorder (Centers for Disease Control and Prevention [CDC], 2020; U.S. Census Bureau, 2020). In comparison to an overlapping time period about 1 year earlier, during January to June 2019 , $8.2 \%$ of U.S. adults had symptoms of depressive disorder (CDC, 2020). In addition, parents self-reported more stress (American Psychological Association, 2020) and declines in mental health during the pandemic (Patrick et al., 2020). Overall, 
there is robust research to suggest a decline in wellbeing during the pandemic. The current study suggested that parental depression was associated with physical and emotional neglect, as well as most of the items measuring parents' reports of having more conflicts and using more discipline toward their children, a finding that is consistent with numerous prior studies showing similar associations (Dubowitz et al., 2011; Lee, 2013; Lee et al., 2012; Mennen \& Trickett, 2011; Stith et al., 2009).

\section{Neglect and COVID-19}

The CTS-PC items used herein assessed several components of child neglect -physical neglect (i.e., not able to provide children with enough food), supervisory neglect (i.e., leaving children unattended when another adult should be with them), emotional neglect (i.e., caught up in own problems and unable to tell child you love them) and neglect related to parental substance use/abuse (i.e., too high or drunk to care for children). Consistent with one other study to date (Bullinger et al., 2020), results of the current study suggest that the conditions of the pandemic may increase risk for neglect. To place these concerns in the broader context, child neglect constitutes $60 \%$ of child maltreatment cases in the U.S. (U.S. Department of Health and Human Services, 2020). Leaving children unattended (Coohey, 2003) and being unable to provide for a child's basic needs are two of the most common forms of child neglect (Hussey et al., 2006; Slack et al., 2004). With parents facing unemployment, it is likely that parents will encounter difficulty meeting children's basic needs. Furthermore, for those parents who are working, supervisory neglect may be especially problematic given the widespread closures of schools and childcare centers, as well as social distancing guidelines limiting other caregivers such as babysitters, grandparents, and neighbors, who may provide care to children under normal circumstances. Supervisory neglect puts children at risk of injuries and accidents, among other concerns (Coohey, 2003; Morrongiello \& Cox, 2019). Substance abuse (i.e., being too drunk or high to care for one's children) is another common risk factor for child maltreatment (U.S. Department of Health and Human Services, 2020). This study suggested that children may be at increased risk for these various forms of neglect during the COVID-19 pandemic.

\section{Emerging Research on Family Wellbeing during COVID-19: Sources of Resilience}

The current study focused on examining risk for child maltreatment during the COVID-19 pandemic. Yet, it is important to note that most children and families are likely to demonstrate enormous resilience during this stressful time. A risk and resilience framework (Prime et al., 2020) describes how both risk-enhancing and protective factors can contribute to wellbeing, even during periods of stress and adversity. When considering factors that may promote wellbeing for parentchild relationships, one study conducted early in the pandemic showed that $53.6 \%$ of parents said they were hugging and showing physical affection toward their child, and the majority of parents reported showing more warmth and love to their children since the pandemic began (Lee et al., 2020). Parents reported that they were spending more time in nearly all child caregiving activities, such as playing, reading, and watching TV with their children (Lee et al., 2020). Over $70 \%$ of parents said they felt supported by their child's school to support their child's education (Lee et al., 2020). This study suggests that some families will adapt to COVID-19, and possibly even benefit from spending more time together. At the same time, children and families who were vulnerable before the pandemic may not have access to as many buffers to promote resilience during the pandemic.

\section{Study Limitations and Future Directions}

The results of the current study may not be generalizable. The parents who responded to this survey were not diverse nor were they at high risk for maltreatment. The sample was mostly White (73.2\%), well educated, and middle-income. Given the sociodemographic advantages of the sample, it is plausible that estimates of the associations between parental perceived social isolation and maltreatment risk are conservative relative to the greater prevalence of these behaviors in more disadvantaged populations. COVID-19 has disproportionately affected socioeconomically disadvantaged individuals and communities of color, in part because the impacts of COVID-19 are exacerbated by underlying socioeconomic and racial inequalities in the U.S. (Fortuna et al., 2020). Future research should consider how chronic stress may exacerbate parenting stress and parental mental health problems during a time of extreme adversity, and how the potential impacts of chronic stress may be particularly challenging among vulnerable families. The current findings showing the potential adverse effects of the pandemic on parenting for a sample with greater resources and buffers may be interpreted to imply even stronger reason for concern among marginalized communities.

The sample size was small, which may have resulted in lack of statistical power in estimating effect sizes. Replicating these analyses utilizing data with a larger sample size would lessen the risk of odds ratios becoming overinflated. Further, many analyses relied on single items (i.e., perceived parental social isolation); future work should consider more robust measurement of these constructs.

The data are cross-sectional; therefore, all estimates are associations and cannot speak to causal mechanisms. The results of this study must be replicated with longitudinal research. Although parents' self-report of maltreatment risk behaviors may be subject to self-report and recall biases, parental 
self-report may be more reliable than administrative records during a time when school personnel, who make the highest percentage of reports to child protection agencies (U.S. Department of Health and Human Services, 2020), are largely unable to identify and report suspected cases of maltreatment (Baron et al., 2020; Jonson-Reid et al., 2020). Future research should consider protective factors and resilience when examining maltreatment risk during the COVID-19 pandemic.

\section{Clinical and Research Implications for Children and Families Following COVID-19}

The highest percentage of child maltreatment reports come from education personnel who are mandated reporters of suspected child maltreatment (U.S. Department of Health and Human Services, 2020). Especially during the early months of the pandemic, most U.S. children were out of school and at home. Thus, education personnel were not able to bring suspected maltreatment to the attention of child welfare authorities. Indeed, child maltreatment reports dropped as much as $70 \%$ during the pandemic (Jonson-Reid et al., 2020). Data has confirmed that school closures likely contributed to declines in maltreatment reports (Baron et al., 2020), thus leaving many children vulnerable to be victims of undetected and unreported maltreatment.

The challenges posed by the pandemic have thus highlighted that the current child welfare system is reliant on unstable systems which already under-identified the true scope of maltreatment. The current reactive approach to child welfare has neglected the importance of prevention, largely responding to the most dire cases of maltreatment (Klika et al., 2018). A public health oriented approach to child welfare would respond to families at multiple levels of care (e.g., through primary and integrated care, school systems, community and church organizations; mental health and community health services), permitting more expanded points of contact for families that would be nimble during times of crises (Herrenkohl et al., 2020; Higgins et al., 2019). Such settings could implement brief, cost-effective screenings that would recognize risks earlier to initiate referrals as needed. Enhanced screening for poverty and economic hardship, trauma exposure, and parenting behaviors that put children at risk during well child visits may be an important step. Safe Environment for Every Kid is an evidence-based program that is uniquely well situated to help health care professional respond to economic strain and parenting stress among their patients (Dubowitz, 2014; Dubowitz et al., 2009). In addition to individual-level interventions to help parents manage economic strain and related parenting stress, there is clearly a need for better policy solutions to support vulnerable families, including federal income supports, direct cash assistance, enhanced food assistance programs, and expanded housing support (Gassman-Pines \& Gennetian, 2020).

In the short-term, there is a need to enhance mental health services to address the challenges of the pandemic and its aftereffects for parents and children. Telehealth services witnessed accelerated adoption (Moreno et al., 2020), which has prompted many to consider how to effectively and safely provide services to vulnerable children and how best to reach parents. One report highlighted the use of video calls, texting, and messaging apps as economical ways for home visitors to connect with parents during the pandemic (Supplee \& Crowne, 2020). The current study findings suggest a need to inquire with parents about their sense of isolation and mental health status. Depression could potentially be detected by routine, cost-effective mental health screening. Such regular brief check-ins may permit triaging those most in need of referrals for more intensive telehealth services (Moreno et al., 2020). Online parent groups can reduce parents' sense of isolation and improving their mental health. Health providers can administer brief screenings and conduct brief virtual check-ins with those at higher-risk. Proactive screenings may help professionals to provide resources to families in need, and can also help to identify parents whose wellbeing is deteriorating as the pandemic persists. When children are at school, schoolbased trauma-informed programs may be especially effective at helping to mitigate the mental health consequences experienced during the pandemic (Herrenkohl et al., 2019).

\section{Conclusion}

The associations between social isolation, employment loss or changes in employment, parental depression, and risk for child maltreatment are notable given that the research was conducted early in the pandemic. Social isolation may be an especially potent risk factor as the pandemic wears on. Even before the pandemic, child maltreatment was a public health crisis in the U.S. (Wildeman, 2018, 2019). There is a need to build a new public health system to prevent child maltreatment (Herrenkohl et al., 2020; Klika et al., 2018) and to provide economic supports to vulnerable families during times of adversity (Gassman-Pines \& Gennetian, 2020) such as those experienced during the global health crisis.

Acknowledgements The authors would like to thank Elizabeth T. Gershoff for comments on an early version of this manuscript, Deborah Schild for conducting expedited Institutional Review Board processes for this study, and Olivia D. Chang for research assistance.

Funding This study was funded in part by the University of Michigan School of Social Work Office of Research. 


\section{Compliance with Ethical Standards}

Conflict of Interest The authors have no financial relationships relevant to this article to disclose and no potential conflicts of interest to disclose.

\section{References}

American Psychological Association. (2020). Stress in America 2020: Stress in the time of COVID-19 (Vol. 1). Washington, DC: American Psychological Association. https://www.apa.org/news/ press/releases/stress/2020/stress-in-america-covid.pdf

Baron, E. J., Goldstein, E. G., \& Wallace, C. T. (2020). Suffering in silience: How COVID-19 school closures inhibit the reporting of child maltreatment. Journal of Public Economics, 190, 104258. https://doi.org/10.1016/j.jpubeco.2020.104258.

Bullinger, L. R., Raissian, K. M., Feely, M., \& Schneider, W. (2020). The neglected ones: Time at home during COVID-19 and child maltreatment. SSRN 3674064. https://papers.ssrn.com/sol3/papers. cfm?abstract id $=3674064$

Cancian, M., Slack, K. S., \& Yang, M. Y. (2010). The effect of family income on risk of child maltreatment. Madison, WI: Institute for Research on Poverty, University of Wisconsin-Madison https:// www.irp.wisc.edu/publications/dps/pdfs/dp138510.pdf.

Centers for Disease Control and Prevention [CDC]. (2020, July). Mental health: Household pulse survey. Atlanta, GA: Centers for Disease Control and Prevention.

Conger, J. C., \& Conger, K. J. (2002). Resilience in Midwestern families: Selected findings from the first decade of a prospective, longitudinal study. Journal of Marriage and Family, 64, 261-373. https://doi. org/10.1111/j.1741-3737.2002.00361.x.

Conrad-Hiebner, A., \& Byram, E. (2020). The temporal impact of economic insecurity on child maltreatment: A systematic review. Trauma, Violence \& Abuse, 21, 157-178. https://doi.org/10.1177/ 1524838018756122.

Conron, K. J., Beardslee, W., Koenen, K. C., Buka, S. L., \& Gortmaker, S. L. (2009). A longitudinal study of maternal depression and child maltreatment in a national sample of families investigated by child protective services. Achives of Pediatrics and Adolescent Medicine, 163, 922-930. https://doi.org/10.1001/archpediatrics.2009.176.

Coohey, C. (2003). Defining and classifying supervisory neglect. Child Maltreatment, 8(2), 145-156. https://doi.org/10.1177/ 1077559502250786.

Dubowitz, H. (2014). The safe environment for every kid (SEEK) model: Helping promote children's health, development, and safety. Child Abuse \& Neglect, 38, 1725-1733. https://doi.org/10.1016/j.chiabu. 2014.07.011.

Dubowitz, H., Feigelman, S., Lane, W., \& Kim, J. (2009). Pediatric primary care to help prevent child maltreatment: The safe environment for every kid (SEEK) model. Pediatrics, 123, 858-864. https:// doi.org/10.1542/peds.2008-1376.

Dubowitz, H., Kim, J., Black, M. M., Weisbart, C., Semiatin, J., \& Magder, L. S. (2011). Identifying children at high risk for a child maltreatment report. Child Abuse \& Neglect, 35, 96-104. https://doi. org/10.1016/j.chiabu.2010.09.003.

Espinosa, A., Ruglass, L. M., Dambreville, N., Shevorykin, A., Nicholson, R., \& Sykes, K. M. (2017). Correlates of child abuse potential among African American and Latina mothers: A developmental-ecological perspective. Child Abuse \& Neglect, 70, 222-230. https://doi.org/10.1016/j.chiabu.2017.06.003.

Fortuna, L. R., Tolou-Shams, M., Robles-Ramamurthy, B., \& Porche, M. V. (2020). Inequity and the disproportionate impact of COVID-19 on communities of color in the United States: The need for a traumainformed social justice response. Psychological Trauma: Theory,
Research, Practice, and Policy., 12, 443-445. https://doi.org/10. $1037 /$ tra0000889443.

Freisthler, B., Johnson-Motoyama, M., \& Kepple, N. J. (2014). Inadequate child supervision: The role of alcohol outlet density, parent drinking behaviors, and social support. Children and Youth Services Review, 43, 75-84. https://doi.org/10.1016/j.childyouth. 2014.05.002.

Gassman-Pines, A., \& Gennetian, L.A. (2020). COVID-19 job and income loss jeopardize child well-being: Income support policies can help (Child Evidence Brief No. 9). Society for Research on Child Development. https://www.srcd.org/research/covid-19-job-andincome-loss-jeopardize-child-well-being-income-support-policiescan-help

Harville, E. W., Taylor, C. A., Tesfai, H., Xiong, X., \& Buekens, P. (2011). Experience of hurricane Katrina and reported intimate partner violence. Journal of Interpersonal Violence, 26, 833-845. https://doi.org/10.1177/0886260510365861.

Hawkins, R. L. (2009). Same at it ever was, only worse: Negative life events and poverty among New Orleans Katrina survivors. Families in Society, 90, 375-381. https://doi.org/10.1177/0886260510365861.

Herrenkohl, T. I., Hong, S., \& Verbrugge, B. (2019). Trauma-informed programs based in schools: Linking concepts to practices and assessing the evidence. American Journal of Community Psychology, 64(3-4), 373-388. https://doi.org/10.1002/ajcp.12362.

Herrenkohl, T. I., Scott, D., Higgins, D. J., Klika, J. B., \& Lonne, B. (2020). How COVID-19 is placing vulnerable children at risk and why we need a different approach to child welfare. Child Maltreatment, 1077559520963916. https://doi.org/10.1177/ 1077559520963916.

Higgins, D., Lonne, B., Scott, D., \& Herrenkohl, T. (2019). The successes and limitations of contemporary approaches to child protection. In D. Higgins, B. Lonne, D. Scott, \& T. Herrenkohl (Eds.), Re-visioning public health approaches for protecting children (pp. 2-24). Switzerland: Springer Nature.

Hussey, J. M., Chang, J. J., \& Kotch, J. B. (2006). Child maltreatment in the United States: Prevalence, risk factors, and adolescent health consequences. Pediatrics, 118(3), 933-942. https://doi.org/10. 1542/peds.2005-2452.

Jonson-Reid, M., Drake, B., Cobetto, C., \& Ocampo, M. G. (2020, April 14). Child abuse prevention month in the context of COVID-19. Washington University in St. Louis: Center for Innovation in Child Maltreatment Policy, Research and Training. https://cicm.wustl.edu/ child-abuse-prevention-month-in-the-context-of-covid-19/

Kim, J., Lee, S. J., Taylor, C. A., \& Guterman, N. B. (2014). Dyadic profiles of parental disciplinary behavior and links with parenting context. Child Maltreatment, 19(2), 79-91. https://doi.org/10.1177/ 1077559514532009.

Klika, J. B., Lee, S. J., \& Lee, J. Y. (2018). Prevention of child maltreatment. In J. B. Klika \& J. R. Conte (Eds.), The APSAC handbook on child maltreatment (4th ed., pp. 235-251). Thousand Oaks, CA: Sage Publications.

Kroenke, K., Strine, T. W., Spitzer, R. L., Williams, J. B. W., Berry, J. T., \& Mokdad, A. H. (2009). The PHQ-8 as a measure of current depression in the general population. Journal of Affective Disorders, 114(1-3), 163-173. https://doi.org/10.1016/j.jad.2008.06.026.

Lee, S. J. (2013). Paternal and household characteristics associated with child neglect and child protective services involvement. Journal of Social Service Research, 39(2), 171-187. https://doi.org/10.1080/ 01488376.2012.744618.

Lee, S. J., Kim, J., Taylor, C. A., \& Perron, B. E. (2011). Profiles of disciplinary behaviors among biological fathers. Child Maltreatment, 16, 51-62. https://doi.org/10.1177/1077559510385841.

Lee, S. J., Taylor, C. A., \& Bellamy, J. L. (2012). Paternal depression and child neglect in father-involved families of young children. Child Abuse \& Neglect, 36, 461-469. https://doi.org/10.1016/j.chiabu. 2012.04.002. 
Lee, S.J., Ward, K.P., Chang, O.D., \& Downing, K.D. (2020). Parenting activities and the transition to home-based education during the COVID-19 pandemic. Children and Youth Services Review, 105585. https://doi.org/10.1016/j.childyouth.2020.105585.

Marcal, K. E. (2018). The impact of housing instability on child maltreatment: A causal investigation. Journal of Family Social Work, 21, 331-347. https://doi.org/10.1080/10522158.2018.1469563.

McConnell, D., Breitkreuz, R., \& Savage, A. (2011). From financial hardship to child difficulties: Main and moderating effects of perceived social support. Child: Care, Health, and Development, 37, 679-691. https://doi.org/10.1111/j.1365-2214.2010.01185.x.

Mennen, F. E., \& Trickett, P. K. (2011). Parenting attitudes, family environments, depression, and anxiety in caregivers of maltreated children. Family Relations, 60, 259-271. https://doi.org/10.1111/j. 1741-3729.20111.00646.x.

Miragoli, S., Balzarotti, S., Camisaca, E., \& DiBlasio, P. (2018). Parents' perception of child behavior, parenting stress, and child abuse potential: Individual and partner influences. Child Abuse \& Neglect, 84, 146-156. https://doi.org/10.1016/j.chiabu.2018.07.034.

Moreno, C., Wykes, T., Galderisi, S., Nordentoft, M., Crossley, N., Jones, N., et al. (2020). How mental health care should change as a consequence of the COVID-19 pandemic. The Lancet Psychiatry, 7, 813-824. https://doi.org/10.1016/S2215-0366(20)30307-2.

Morrongiello, B., \& Cox, A. (2019). Issues in defining and measuring supevisory neglect and conceptualizing prevention. Child Indicators Research, 13, 369-385. https://doi.org/10.1007/s12187-019-096533.

Muthén, L. K., \& Muthén, B. O. (1998-2017). Mplus user's guide (8th ed.). Los Angeles, CA: Muthén \& Muthén.

Neppl, T. K., Senia, J. M., \& Donnellan, M. B. (2016). Effects of economic hardship: Testing the family stress model over time. Journal of Family Psychology, 30, 12-21. https://doi.org/10.1037/ fam0000168.

Nylund, K. L., Asparouhov, T., \& Muthen, B. O. (2006). Deciding on the number of classes in latent class analysis and growth mixture modeling: A Monte Carlo simulation study. Unpublished manuscript, Graduate School of Education \& Information Studies, University of California, Los Angeles. Los Angeles, California.

Ono, M., \& Honda, S. (2017). Association between social support and child abuse potential among Japanese mothers. Children and Youth Services Review, 73, 88-92. https://doi.org/10.1016/j.childyouth. 2016.12.003.

Palan, S., \& Schitter, C. (2018). Prolific.ac - a subject pool for online experiments. Journal of Behavioral and Experimental Finance, 17, 22-27. https://doi.org/10.1016/j.jbef.2017.12.004.

Patrick, S. W., Henkhaus, L. E., Zickafoose, J. S., Lovell, K., Halvorson, A., Loch, S., Letterie, M., \& Davis, M. M. (2020). Well-being of parents and children during the COVID-19 pandemic: A national survey. Pediatrics, 146(4), e2020016824.

Prime, H., Wade, M., \& Browne, D. T. (2020). Risk and resilience in family well-being during the COVID-19 pandemic. American Psychologist, 75, 631-643. https://doi.org/10.1037/amp0000660.

Rodriguez, C. M., Smith, T. L., \& Silvia, P. J. (2016). Parent-child aggression risk in expectant mothers and fathers: A multimethod theoretical approach. Journal of Child and Familty Studies, 25, 32203235. https://doi.org/10.1007/s10826-016-0481-y.

Rodriguez, C. M., Silvia, P. J., \& Pu, D. F. (2018). Predictors of change in mothers' and fathers' parent-child aggression risk. Child Abuse \& Neglect, 86, 247-256. https://doi.org/10.1016/j.chiabu.2018.09. 008.

Rodriguez, C. M., Lee, S. J., Ward, K. P., \& Pu, D. F. (2020). The perfect storm: Hidden risk of child maltreatment during the COVID-19 pandemic. Child Maltreatment. https://doi.org/10.1177/ 1077559520982066.

Schaeffer, C. M., Alexander, P. C., Bethke, K., \& Kretz, L. S. (2005). Predictors of child abuse potential among military parents:
Comparing mothers and fathers. Journal of Family Violence, 20, 123-129. https://doi.org/10.1007/s10896-005-3175-6.

Schneider, W., Waldfogel, J., \& Brooks-Gunn, J. (2017). The great recession and risk for child abuse and neglect. Children and Youth Services Review, 72, 71-81. https://doi.org/10.1016/j.childyouth. 2016.10.016.

Seddighi, H., Salmani, I., Javadi, M. H., \& Seddighi, S. (2019). Child abuse in natural disasters and conflicts: A systematic review. Trauma, Violence, \& Abuse., 22, 176-185. https://doi.org/10. $1177 / 1524838019835973$.

Slack, K. S., Holl, J. L., Lee, B. J., McDaniel, M., Yoo, J., \& Bolger, K. (2004). Understanding the risks of child neglect: An exploration of poverty and parenting characteristics. Child Maltreatment, 9(4), 395-408. https://doi.org/10.1177/1077559504269193.

Slack, K. S., Berger, L. M., Dumont, K., Yang, M. Y., Kim, B., EhrhardDietzel, S., \& Holl, J. L. (2011). Risk and protective factors for child neglect during early childhood: A cross-study comparison. Children and Youth Services Review, 33(8), 1354-1363. https://doi.org/10. 1016/j.childyouth.2011.04.024.

Smith Slep, A. M., \& O’Leary, S. G. (2007). Multivariate models of mothers' and fathers' aggression toward their children. Journal of Consulting and Clinical Psychology, 75, 739-751. https://doi.org/ 10.1037/0022-006X.75.5.739.

Stith, S. M., Liu, T., Davies, C., Boykin, E. L., Alder, M. C., Harris, J. M., et al. (2009). Risk factors in child maltreatment: A meta-analytic review of the literature. Aggression and Violent Behavior, 14(1), 13-29. https://doi.org/10.1016/j.avb.2006.03.006.

Straus, M. A., Hamby, S. L., Finkelhor, D. W., Moore, D. W., \& Runyan, D. (1998). Identification of child maltreatment with the parent-child conflict tactics scales: Development and psychometric data for a national sample of American parents. Child Abuse \& Neglect, 22, 249-270. https://doi.org/10.1016/s0145-2134(97)00174-9.

Supplee, L, \& Crowne, S.S. (2020, March 26). During the Covid-19 pandemic, telehealth can help connect home visiting services to families. https://www.childtrends.org/during-the-covid-19pandemic-telehealth-can-help-connect-home-visiting-services-tofamilies

The White House, Office of the Press Secretary. (2020, March 16). The President's coronavirus guidelines for America: 15 days to slow the spread. Retrieved from https://www.justice.gov/doj/page/file/ 1258511/download

Tracy, M., Salo, M., \& Appleton, A. A. (2018). The mitigating effects of maternal social support and paternal involvement on the intergenerational transmission of violence. Child Abuse \& Neglect, 78, 46-59. https://doi.org/10.1016/j.chiabu.2017.09.023.

Tucker, M. C., \& Rodriguez, C. M. (2014). Family dysfunction and social isolation as moderators between stress and child physical abuse risk. Journal of Family Violence, 29, 175-186. https://doi.org/10.1016/j. chiabu.2017.04.030.

Tucker, M. C., Rodriguez, C. M., \& Baker, L. R. (2017). Personal and couple level risk factors: Maternal and paternal parent-child aggression risk. Child Abuse \& Neglect, 69, 213-222. https://doi.org/10. 1016/j.chiabu.2017.04.030.

U.S. Census Bureau. (2020, June). Measuring household experiences during the coronavirus (COVID-19) pandemic. Retrieved from https://www.census.gov/householdpulsedata

U.S. Department of Health and Human Services. (2020). Child Maltreatment, 2018. Retrieved from https://www.acf.hhs.gov/cb/ resource/child-maltreatment-2018

U.S. Department of Labor. (2020, March). News release: Unemployment insurance weekly claims. Washington, DC: U.S. Department of Labor.

Wang, C., Pan, R., Wan, X., Tan, Y., Xu, L., Ho, C. S., \& Ho, R. C. (2020). Immediate psychological responses and associated factors during the initial stage of the 2019 coronavirus disease (COVID-19) epidemic among the general population in China. International 
Journal of Environmental Research and Public Health, 17, 1729. https://doi.org/10.3390/ijerph17051729.

Wildeman, C. (2018). The incredibly credible prevalence of child protective services contact in New Zealand and the United States. American Journal of Public Health, 108(4), 438-439. https://doi. org/10.2105/AJPH.2018.304313.

Wildeman, C. (2019). Editorial: How badly do we undercount chronic maltreatment, and how much should clinicians care? Journal of the American Academy of Child \& Adolescent Psychiatry, 58(12), 1152-1153. https://doi.org/10.1016/j.jaac.2019.07.004.

Wildeman, C., Emanuel, N., Leventhal, J. M., Putnam-Hornstein, E., Waldfogel, J., \& Lee, H. (2014). The prevalence of confirmed maltreatment among US children, 2004 to 2011. JAMA Pediatrics, 168, 706-713. https://doi.org/10.1001/jamapediatrics.2014.410.

Wood, J. N., Medina, S. P., Feudtner, C., Luan, X., Localio, R., Fieldston, E. S., \& Rubin, D. M. (2012). Local macroeconomic trends and hospital admissions for child abuse, 2000-2009. Pediatrics, 130, e358-e364. https://doi.org/10.1542/peds.2011-3755.

World Health Organization. (2020a, March 11). WHO director-general's opening remarks at the media briefing on COVID-19-11 March 2020 [speech transcript]. Retrived online from: https:// www.who.int/dg/speeches/detail/who-director-general-s-openingremarks-at-the-media-briefing-on-covid-19\%2D\%2D-11-march2020

World Health Organization. (2020b, April 27). WHO timeline - COVID19. Retrieved online from: https:/www.who.int/news-room/detail/ 27-04-2020-who-timeline\%2D\%2D-covid-19

Publisher's Note Springer Nature remains neutral with regard to jurisdictional claims in published maps and institutional affiliations. 